\title{
Effects of Twelve Week Multi-Skills Movement Programme On Motor Development in 7-10 Years Old Boys
}

\author{
Ersoz Y', Bediz CS 2 \\ ${ }^{1}$ Faculty of Sport Science, Mersin University, Mersin, Turkey. \\ ${ }^{2}$ Faculty of Medicine Basic Medical Sciences Department of Physiology, Dokuz Eylül \\ University, İzmir,
}

\begin{abstract}
Motor development is an important factor affecting the health status physically, psychologically and socially in both childhood and adulthood. It is important to develop motor skills starting from childhood and to participate in a variety of physical activities for this. In this study, it is aimed to reveal the motor development of 7-10 years old boys who receive multi-skill movement training outside of school and to examine the developmental differences. 61 volunteer college students participated in the study, the sample was divided into 31 students as a control group and 30 students as an intervention group receiving multi-skill movement training outside of school. The Test of Gross Motor Development-2 test, which includes locomotor and object control skill subtests, was applied to monitor the motor development of the children participating in the study. Gross motor skill scores from these two subtests were evaluated. At the end of the 12-week movement program, the study group showed a statistically significant improvement in gross motor skills, object control and locomotor sub-skills compared to the control group. A statistically significant improvement was found only in the object control sub-skill in the control group, whose in-school movement education continued. As a result, physical education activities at schools should be evaluated in terms of their duration and content, and children's participation in physical activities that show diversity should be evaluated in terms of motor development.
\end{abstract}

Key Words: Motor Development, Gross Motor Development, TGMD-2, Multi-Skills 


\section{Introduction}

Childhood is a critical period for the development of basic movement skills; because the neurological capacity to learn basic movement skills is most present in this period (Gallahue \& Donnelly, 2003). It has been found that there is a linear relationship between preschool and adolescent children having insufficient basic movement skills and inactive life (Hume et al. 2008; Williams et al. 2008). Clark and Metcalfe (2002) stated that the lack of development of basic locomotor and object control skills in children causes physical activity limitations in later ages. In addition, Whitall (2003) suggested that the development of motor skills in children contributes to the development of perceptual, cognitive and emotional processes. Gallahue, Ozmun, and Goodway (2019) stated that, in the hourglass model of motor development, children between the ages of 7-10, who are at the beginning of the school age, are in the transition stage in terms of movement phase. Therefore, they said that care should be taken in order not to customize or restrict the activity-related movements of children in this period. They also stated that a narrow focus on skills during this stage can have negative effects for the other specialized movement periods.

Diverse in-school and out-of-school activities for this age group can offer opportunities to develop basic motor skills. Physical education lesson plans in terms of in-school activities have recently undergone intensive development and many changes. Despite the initiatives of physical education experts, PE teachers, students and parents still struggle with a range of problems, sometimes more, sometimes less successfully. UNESCO's Worldwide Survey of School Physical Education report revealed evidence that national governments promised to allocate sufficient physical education classes through legislation, but some countries are slow or inadequate in terms of implementation quality (Murphy, Routen \& Tones, 2014). There are thoughts that some shortcomings are present in the quantity and quality of physical education classes around the world (Amusa, Toriola \& Goon, 2013; Block \& Obrusnikova, 2007; Hardman, 2002; Hickson, Robinson, Berg \& Hall, 2010; Lieberman, Houston-Wilson \& Kozub, 2002; Sugino \& Mimura, 2013; Vickerman, 2007). For this reason, out-ofschool sports activities can provide a favorable environment for the physical, cognitive and social development of children.

Multi-skill movement training, which aims to develop basic movement skills among out-of-school sports activities, is applied in many private centers. However, little is known about the impact of these programs on basic movement skills. Bakhtiari et al. (2011) stated that the experimental group of female third graders from primary school participating in the movement program selected for eight-week motor development, except for the Physical Education lesson, showed a high level of motor development. Fowheather et al. (2008), on the other hand, found that a longer period of time should be 
applied to evaluate whether the nine-week training program is effective for children who attend a club that provides multi-skill training after school. In addition, the increase in physical activity level and movement skills brought by multi-skill training also positively affects children's levels of fitness, perceived physical competence, physical self-perceptions and psychological health in children's lives. There are results of this research in the literature (Fox \& Wilson, 2008; Crocker, Eklund, \& Kowalski, 2000; Okely, Booth, \& Chey, 2004; Welk \& Eklund, 2005; Wrotniak, Epstein, Dorn, Jones, \& Kondilis, 2006). Besides researches on this subject contribute to the physical, psychological and social health of children, it will be useful for researchers and experts (e.g., physical education teacher, trainer) who make applications in this field.

In this direction, the aim of the study is to examine the effect of the after-school multi-skill movement program designed to increase motor skill competence for 12 weeks on locomotor skills, manipulative skills and gross motor skills (total skill score) in boys aged 7-10 years. For this purpose, the hypotheses of the research are given below.

$\mathrm{H}_{1}$ : The 12-week multi-skill training program increases the locomotor skill level in boys between the ages of 7-10.

$\mathrm{H}_{2}$ : The 12-week multi-skills training program increases the level of object control skills in boys aged 7-10 years.

$\mathrm{H}_{3}$ : The 12-week multi-skills training program increases the level of gross motor skills (total skill score) in boys aged 7-10 years.

\section{Participants}

\section{Method}

61 male volunteer students between the ages of 7-10 studying at a private school participated in the research. The inclusion criteria of the study were determined as children who agreed to participate in the study, being healthy and not having a known medical problem that could affect motor competence. Among the participants, 30 male students studying in a multi-skill sports club ( $\mathrm{M}$ age $=7.1$ yr $\mathrm{SD}=0.9$ ) formed the intervention group, 31 male students who did not participate in a sports activity outside of school ( $\mathrm{M}$ age $=7.5 \mathrm{yr} \mathrm{SD}=1$ ) formed the control group. While 42 volunteer students from the multi-skill club were included in the intervention group before the study, 12 students were excluded from the study because they did not complete the 12-week program. Again, 17 students from the control group were excluded from the study because they did not participate in the posttest measurements for different reasons. The fact that the students participating in the research study in different schools leads to a weak group equivalence, but the students who are close to each other in terms of socioeconomic level who study at private paid private schools with the same opportunities were included in the study and the group equivalence was achieved as much as possible. 
Before starting the study, parents of the students were informed about the research with an informed consent form and approval of the university ethics committee was obtained.

\section{Assessment of Gross Motor Development}

The Test of Gross Motor Development-2 (TGMD-2) was performed to measure the gross motor skills of the intervention and control groups. TGMD-2 is a validated, criterion- and norm-referenced process-oriented assessment that was designed to qualitatively evaluate gross motor skill performance of children between the ages of three and ten years (Ulrich, 2000). The TGMD-2 is an appropriate tool for assessing the motor skills of children in different populations around the world(Valentini, 2012; Kim, Kim, Valentini \& Clark,2014; Farrokhi, Zareh, KarimiAlvar, Kzaemnejad\& Ilbeigi,2014; Lopes, Saraiva \& Rodrigues,2018).

In the evaluation of the TGMD-2 test, 6 locomotor tests each consisting of 3 to 5 criteria (running, gallop, jumping, leg spreading, two-leg jumping, slipping) and 6 object control tests (hitting the ball, dribbling, catching, kicking, up ball throw, ball rolling) are scored as 1 or 0 points based on successful application or failure of skill criteria through observation. Two trials were conducted for each skill, and the collected scores determined the total score of locomotor and object control subtests. Scores obtained from locomotor and object control subtests were converted to standard scores according to age, and gross motor skill scores were determined from the sum of these standard scores.

Measurements were made in the gym for both groups. Before starting the test application, the skill stations to be applied to the children in general were explained. It was determined which hand and foot the children used before transferring to the skill station. Verbal and visual narration was given at each skill station. No suggestions or corrections were made while applying the movement. For evaluation, tests were recorded with the camera and camera shots were used in the same angle arrangement according to the stations where the skills were applied. The scoring of the criteria in the evaluation of TGMD-2 test was done by one researcher by slowing down the normal play speed by $1 / 4$ in the media player.

Body Weight and Height Measurement: Body weight and height measurements were measured with appropriate clothes and bare feet using SECA brand stadiometer before the test application.

\section{Procedure}

A pretest-posttest nonequivalent comparison group design was used in this study. An overview of the study design and measurements taken are given in Table 1. 
Table 1: Overview of the study.

\begin{tabular}{|c|c|c|}
\hline$\downarrow$ & Intervention group $(\mathrm{n}=30)$ & $\downarrow$ \\
\hline Pre-Test & Interventions (12 weeks) & Post-Test \\
\hline $\begin{array}{l}\text { Test Of Gross Motor } \\
\text { Development } \\
\text { Locomotor Test } \\
\text { Object Control Test }\end{array}$ & $\begin{array}{l}\text { Multi-Skills Movement Program } \\
\text { Fitness, Educationalm Games, Football, Swimming, Tenis, } \\
\text { Hockey, Gymnastic, Step-Aerobic, Handball, Beseball, } \\
\text { Basketball, Traditional Games, Voleyball, Table Tenis, } \\
\text { Taekwondo, Badminton, Copoeria }\end{array}$ & $\begin{array}{l}\text { Test Of Gross Motor } \\
\text { Development } \\
\text { Locomotor Test } \\
\text { Object Control Test }\end{array}$ \\
\hline & $=31)$ & $\hat{\imath}$ \\
\hline
\end{tabular}

The multi-skill movement program of the intervention group was given in Junior Academy Sport, a sports facility that runs a multi-movement program by experienced trainers with various coaching qualifications and trained in the faculty of sports science. In the 12-week multi-skill movement program, children aged 7-10 received 72 hours of movement training in 17 different sports branches, 4 days a week for a total of 1.5 hours a day (Table.2). In the sports branches selected for movement training, the course contents for the program consist of fun games for the development of basic skills and basic applications of the sports branch. The application program has been created by academics working in the field of children and sports, who conduct multi-skill club consultancy. After-school multi-skills movement program intervention was not applied to the control group. The students in the control group were asked to follow their normal routines and not to participate in out-of-school sports programs during the intervention period. 
Table 2: Multi-Skills Movement Programme

\begin{tabular}{|c|l|c|c|c|}
\hline \multicolumn{1}{|c|}{ Multi-Skils Programme } & 7 years old & $\mathbf{8 - 9}$ years old & 10 years old \\
\hline $\mathbf{1}$ & Fitness & $3 \mathrm{hr}$ & $3 \mathrm{hr}$ & $3 \mathrm{hr}$ \\
\hline $\mathbf{2}$ & Educational Games & $6 \mathrm{hr}$ & $6 \mathrm{hr}$ & $3 \mathrm{hr}$ \\
\hline $\mathbf{3}$ & Football & $6 \mathrm{hr}$ & $6 \mathrm{hr}$ & $6 \mathrm{hr}$ \\
\hline $\mathbf{4}$ & Swimming & $6 \mathrm{hr}$ & $6 \mathrm{hr}$ & $6 \mathrm{hr}$ \\
\hline $\mathbf{5}$ & Tenis & $6 \mathrm{hr}$ & $6 \mathrm{hr}$ & $6 \mathrm{hr}$ \\
\hline $\mathbf{6}$ & Hockey & $3 \mathrm{hr}$ & $3 \mathrm{hr}$ & $3 \mathrm{hr}$ \\
\hline $\mathbf{7}$ & Gymnastic & $6 \mathrm{hr}$ & $6 \mathrm{hr}$ & $6 \mathrm{hr}$ \\
\hline $\mathbf{8}$ & Step-Aerobic & $\mathrm{x}$ & $3 \mathrm{hr}$ & $3 \mathrm{hr}$ \\
\hline $\mathbf{9}$ & Handball & $6 \mathrm{hr}$ & $6 \mathrm{hr}$ & $6 \mathrm{hr}$ \\
\hline $\mathbf{1 0}$ & Beseball & $3 \mathrm{hr}$ & $3 \mathrm{hr}$ & $3 \mathrm{hr}$ \\
\hline $\mathbf{1 1}$ & Basketball & $6 \mathrm{hr}$ & $6 \mathrm{hr}$ & $6 \mathrm{hr}$ \\
\hline $\mathbf{1 2}$ & Traditional Games & $6 \mathrm{hr}$ & $3 \mathrm{hr}$ & $3 \mathrm{hr}$ \\
\hline $\mathbf{1 3}$ & Voleyball & $6 \mathrm{hr}$ & $6 \mathrm{hr}$ & $6 \mathrm{hr}$ \\
\hline $\mathbf{1 4}$ & Table Tenis & $\mathrm{x}$ & $3 \mathrm{hr}$ & $3 \mathrm{hr}$ \\
\hline $\mathbf{1 5}$ & Taekwondo & $3 \mathrm{hr}$ & $3 \mathrm{hr}$ & $3 \mathrm{hr}$ \\
\hline $\mathbf{1 6}$ & Badminton & $6 \mathrm{hr}$ & $3 \mathrm{hr}$ & $3 \mathrm{hr}$ \\
\hline $\mathbf{1 7}$ & Copoeria & $\mathrm{x}$ & $\mathrm{x}$ & $3 \mathrm{hr}$ \\
\hline & & \multicolumn{2}{|c|}{} \\
\hline
\end{tabular}

Statistical analysis: Descriptive statistical analysis (mean, standard deviation, frequency, minimum and maximum value) was performed in order to define the characteristics of the research group in the analysis of the data. Data suitability for normal distribution was evaluated with the Kolmogorov Smirnov test and it was determined that the data were distributed normally. Therefore, parametric measurement methods were used to analyze the data obtained from the research. Paired sample t-test was used in the analysis of repeated measurements within the group, and IndependentSample t test was used in the comparison of data between groups. Significance level was taken as $\mathrm{p}<0.05$. Percentage change of participants between 1st and 2nd measurement was calculated with the formula: \% $\%$ : (2nd measurement-1st measurement) / 1st measurement*100 


\section{Results}

As a result of the independent group t-test conducted to compare the groups participating and not participating in the multi-skill movement program, it was found that there was no statistically significant difference in the characteristics of the participants such as body weight and height(Table 3).

Table 3: Comparison of Physical Properties of Intervention and Control Groups

\begin{tabular}{|c|c|c|c|c|}
\hline & & $\mathbf{X}$ & $\mathbf{t}$ & $\mathbf{p}$ \\
\hline \multirow{2}{*}{ Age (year) } & Intervention & $7.6 \pm 0.9$ & \multirow{2}{*}{0,32} & \multirow{2}{*}{0.74} \\
\hline & Control & $7.5 \pm 1$ & & \\
\hline \multirow{2}{*}{ Body Weight (kg) } & Intervention & $29.9 \pm 9.8$ & \multirow{2}{*}{0,86} & \multirow{2}{*}{0,39} \\
\hline & Control & $31.9 \pm 8.5$ & & \\
\hline \multirow{2}{*}{ Height (cm) } & Intervention & $128 \pm 9$ & \multirow{2}{*}{$\begin{array}{c}-1,68 \\
158\end{array}$} & \multirow{2}{*}{0,1} \\
\hline & Control & $131 \pm 8.9$ & & \\
\hline
\end{tabular}

Table 4: Intervention Group Repeated Measuring Values

\begin{tabular}{lccc} 
& \multicolumn{2}{c}{ Intervention $(\mathrm{n}=30)$} \\
\cline { 2 - 2 } Locomotor & Pre & & Post \\
\cline { 2 - 3 } Object Control & $36,5 \pm 5,3$ & & $40,3 \pm 4,4^{* * *}$ \\
Gross Motor & $87 \pm 9,4$ & & $41,4 \pm 4,8^{* * *}$ \\
\hline
\end{tabular}

TGMD-2 scores before movement program (Pre); after movement program (Post);

$*: \mathrm{p}<0.05,^{* *}: \mathrm{p}<0,01,{ }^{* * *}: \mathrm{p} 0.001$ Mean \pm SD.

There is a statistically significant difference between the mean scores of "locomotor skill", "object control" and "total skill" in the pretest and posttest results of the participants $(\mathrm{p}<0.01)$. Posttest results of motor skills of individuals participating in multiple training programs are higher than pretest results(Table 4). 
Table 5: Repeated Measurement Values of Control Group

\begin{tabular}{lccc}
\hline & \multicolumn{2}{c}{ Control $(\mathrm{n}=31)$} \\
\cline { 2 - 2 } Locomotor & Pre & & Post \\
\cline { 2 - 3 } Object Control & $39,4 \pm 4$ & & $40,2 \pm 4,2$ \\
Gross Motor & $91 \pm 10,4$ & & $38,8 \pm 5,5^{* * *}$ \\
\hline
\end{tabular}

TGMD-2 scores before movement program (Pre); after movement program (Post);

$*: \mathrm{p}<0.05,{ }^{* *}: \mathrm{p}<0,01, * * *: \mathrm{p} 0.001$, Mean \pm SD.

There is a statistically significant difference between the mean "object control" scores of the participants in the pre-test and post-test results $(p<0.001)$. The posttest results in the "object control" dimension of the motor skill of the individuals who did not participate in the multiple training program were higher than the pretest results(Table 5).

Table 6: Comparison of Motor Skill Characteristics of Intervention and Control Groups

\begin{tabular}{|c|c|c|c|c|c|c|}
\hline & \multicolumn{3}{|c|}{ Intervention $(\mathrm{n}=30)$} & \multicolumn{3}{|c|}{ Control (n=31) } \\
\hline & Pre & Post & $\% \Delta$ & Pre & Post & $\% \Delta$ \\
\hline Locomotor & $36,5 \pm 5,3$ & $40,3 \pm 4,4$ & $11,2^{* * *}$ & $39,4 \pm 4 *$ & $40,2 \pm 4,2$ & 2,1 \\
\hline Object Control & $37,7 \pm 5,4$ & $41,4 \pm 4,8$ & $10,6^{* * *}$ & $37,4 \pm 6,2$ & $38,8 \pm 5,5$ & 4,4 \\
\hline Gross Motor & $87 \pm 9,2$ & $97,1 \pm 11,32$ & $11,8^{* * *}$ & $91 \pm 10,4$ & $92,9 \pm 10$ & 2,3 \\
\hline
\end{tabular}

TGMD-2 scores before movement program (Pre); after movement program (Post);

$*: \mathrm{p}<0.05$, $^{* *}: \mathrm{p}<0,01, * * *: \mathrm{p} 0.001, \% \Delta: 2-1 / 1 \times 100$, Mean $\% \Delta$ percent change, Mean \pm SD.

In the comparison of motor development characteristics between groups, when the pretest measurements of the two groups were compared, no difference was found between the object control skill values. Locomotor skill values are significantly higher in the control group. However, there was no difference between the total skill values of the two groups. When the posttest measurements of the two groups were compared at the end of the multi-skill training period, the posttest measurement values did not differ significantly between the two groups. On the other hand, when the differences between the pre-test and post-test measurements of the two groups are compared $(\% \Delta$ : percentage distribution), the \% increase in all three dimensions of motor development in the intervention group was statistically significantly higher than in the control group(Table 6). 


\section{Discussion}

This study aimed to examine the gross motor development of boys between the ages of 7-10 who receive multi-skill movement training outside of school, and the research findings support the hypothesis that the out-of-school multi-skill training program will improve gross motor skills and its subcomponents, which are locomotor and manipulative skills.

Studies in the literature have shown that there is a positive relationship between children's participation in organized physical activity and their basic movement skills performance (Fahimi et al., 2013, Robinson, 2011, Vandorpe et al., 2012). Although the motor development test batteries used and the content and duration of the selected skill movement programs differ, the sample groups showed that the effects of organized physical activity programs outside of school on the progression of basic movement skills Wang (2004), Sheik (2011), Akbari (2009) Bakhtiari 2011) also confirms their research. Akbari et al. (2009) revealed that traditional games for 8 weeks as an activity outside of school have quite positive effects on the development of motor skills in boys aged 7-9 years. Bakhtiari et al. (2011) stated that the experimental group of female third graders participating in the movement program selected for eight-week motor development, except for the Physical Education lesson, showed a high level of motor development. These two studies are similar to our research in terms of the test battery used to reveal motor development, the selected extracurricular activity program and its findings, both gross motor skills and locomotor and object control subcomponents significantly improved in the application groups. Sheikh (2011) and Wang (2004) examined the effects of selected movement program applications on motor development in preschool children using different developmental test batteries. Thus, Sheikh (2011) et al. did not observe a significant difference on development in coordination skills in both genders in preschool children aged 5-6 years, and again Wang et al. (2004) did not show a significant difference on development in locomotor skills in children aged 3-5, and object control skills. In the preschool period, some motor skills of the chosen movement program, which was applied in addition to the education, improved. Although Lennart and Päll (2006) did not implement an out-of-school movement program, in their study, in which primary school children evaluated the level of out-ofschool physical activities with a modified observational method and the intensity of their out-of-school physical activities using an accelerometer, they evaluated the development levels of primary school children. They made it clear that the level of development of the skill (throwing ball and jumping) was related to the skill-specific physical activity outside of school, and was not related to the general level of physical activity. Contrary to these studies, when compared the control and study group, Foweather et al. (2008) did not reveal significant improvement in gross motor skills such as jumping, sprinting, hitting the ball, and catching, except for static balance, in 
children who attended the after-school multi-skill training club for 9 weeks. The findings may have differed in terms of the weak numerical power of the sample group due to the fact that the study was a trial study, and also that the research groups were not separated according to the gender variable. Regarding the effect of different physical education interventions at school on motor development other than after-school activities, Pagona and Costas (2008) applied a specially prepared physical education curriculum to 9-year-old children studying in the third grade and evaluated it in terms of motor development at the age of 9, 10 and 18. The study group showed a significant improvement in all three periods compared to the control group. In this study, it was emphasized that apart from the effects of the special program, the effects of the developmental process and the motor skills acquired in childhood could potentially remain active for the rest of their life. From this point of view, Physical Education classes for the motor development of children are the most common organized physical activity accessible to all children in education, but in many countries it raises many questions about its sufficiency in terms of duration, content and application (Murphy, Routen \& Tones, 2014). Therefore, the effects of different Physical Education curricula on the development of children have been revealed in the literature (Sallis, McKenzie, Alcaraz, Kolody, Faucette \& Hovell, 1997; McKenzie, Alcaraz, Sallis \& Faucette, 1998; Kelder, Mitchell, McKenzie, Derby, Strikmiller, Luepker \& Stone, 2003; Jan, 2009). In our research findings, a significant improvement was observed in object control skills, which is a subcomponent of gross motor skills, in the control group who participated in organized physical activity only with the Physical Education course. Regarding this development, it may be related to the activities of popular team sports (football, basketball, volleyball, etc.) activities that include more object control skills in physical education lessons and the presence of suitable areas for these sports branches in the school gardens (basketball hoop, football goal, volleyball net, etc.) and optional use by children. Demirhan et al. (2008) pointed out "lack of facilities, insufficient course hours and lack of equipment" as the three most important problems and shortcomings during lessons in their research on the execution of the physical education curriculum and programs in Turkey. In addition, according to physical education teachers, they revealed that the five activities that should take place in physical education classes with the highest percentage value are volleyball, basketball, tennis, football and swimming, respectively. According to the students, this order happened to be volleyball, swimming, scouting, football and basketball. The intensity of popular team sports among both teachers' and students' selection of activities shows this trend.

Although these multi-skill movement training experiences of children are effective in motor skill development, individuals' physical dimensions, age, gender, inheritance and past experiences and the development of each of these aspects may reveal differences, especially in periods when the development is rapid (Espenschade, 
1940). Although there are motor skill factors related to development among the age group participating in our study, the TGMD-2 test battery we used in our study to evaluate the motor skill performance corrected the subtest motor skill scores varying in different age groups to allow a consistent progression at age level with standard scoring. There are studies showing that motor skill performance is negatively affected in obese children regarding motor skill performance in terms of physical measures (Okely, Booth \& Chey, T, 2004; Graf, Koch, Kretschmann-Kandel, Falkowski, Christ, Coburger \& Predel, 2004; Castetbon \& Andreyeva, 2012; Lopes, Stodden, Bianchi, Maia \& Rodrigues, 2012). D'Hondt (2011) found that childhood overweight and especially obesity in children negatively affected gross motor skill performance, even considering maturity differences in boys and girls aged 5 to 12 years. Most notably, differences in body mass index have become more pronounced in older age groups of children. Although we did not determine the body mass index of our research groups, it showed that there was no statistically significant difference between the two groups in the physical characteristics of children such as body weight and height.

As a result, this study emphasizes the review of the effectiveness of Physical Education lessons, which have been revealed as a result of many studies, and to ensure that children participate in a variety of post-school physical activities that will increase their basic movement skills for their physical, cognitive, affective and social development, which are important for a lifelong healthy life. Multiple skill development programs that will provide this diversity may vary depending on many factors such as duration, content, application methods and practitioner performance. In addition, it is also important how much the developments achieved in these programs are transferred to later periods. Therefore, application contents, methods and follow-up findings of multiskill development programs should be reviewed in future studies.

'The Author(s) declare(s) that there is no conflict of interest'.

Note: This publication is produced from Yasin Ersöz's doctoral dissertation. 


\section{References}

Amusa, L.O., Toriola, A.L., and Goon, T.D. (2013). Physical Education and School Sport in South Africa. The Global Journal of Health and Physical Education Pedagogy, 2 (3), pp. 187-196.

B. Vandorpe, J. Vandendriessche, R. Vaeyens, J. Pion, S. Matthys, J. Lefevre, et al.Relationship between sports participation and the level of motor coordination in childhood: a longitudinal approach Journal of Science and Medicine in Sport, 15 (3) (2012), pp. 220-225

Bakhtiari S., Shafinia P., Ziaee V .Effects of selected exercises on elementary school third grade girl students' motor development.Asian Journal of Sports Medicine, 2011; 2: $51-56$

Block, M. E., and Obrusnikova, I. (2007). What is inclusion? In M.E. Block (Ed.), A teacher's guide to including children with disabilities in general physical education (3rd ed)Baltimore: P. H. Brookes. pp.15-28.

Cano-Cappellacci, M., Leyton, F. A., \& Carreño, J. D. (2016). Content validity and reliability of test of gross motor development in Chilean children. Revista de saude publica, 49, 97.

Castetbon, K., \& Andreyeva, T. (2012). Obesity and motor skills among 4 to 6-year-old children in the United States: nationally-representative surveys. BMC pediatrics, 12(1), 28.

Clark, J. E., \& Metcalfe, J. S. (2002). The mountain of motor development: A metaphor. Motor development: Research and reviews, 2(163-190), 183-202.

Crocker, P. R., Eklund, R. C., \& Kowalski, K. C. (2000). Children's physical activity and physical self-perceptions. Journal of sports sciences, 18(6), 383-394.

Demirhan, G., Bulca, Y., Altay, F., Şahin, R., Güvenç, A., Aslan, A., ... \& Açıkada, C. (2008). Beden eğitimi öğretim programları ve programların yürütülmesine ilişkin paydaş görüşlerinin karşılaştırılması. Spor Bilimleri Dergisi, 19(3), 157-180.

D'Hondt, V., Deforche, B., Vaeyens, R., Vandorpe, B., Vandendriessche, J., Pion, J., ... \& Lenoir, M. (2011). Gross motor coordination in relation to weight status and age in 5- 
to 12-year-old boys and girls: a cross-sectional study. International journal of pediatric obesity, 6(sup3), e556-564.

Espenschade, A. (1940). Motor performance in adolescence including the study of relationships with measures of physical growth and maturity. Monographs of the Society for Research in Child Development, 5(1), i-126.

Farrokhi, A., Zareh Zadeh, M., Karimi Alvar, L., Kzaemnejad, A., \& Ilbeigi, S. (2014). Reliability and validity of test of gross motor development-2 (Ulrich, 2000) among 3-10 aged children of Tehran City. Journal of Physical Education and Sports Management, 5(2), 18-28.

Foweather L., Whannell N. , Henaghan J . Lees A., Effect of a 9-week. after-school Multiskills club on fundamental movement skill proficiency in 8- to 9-yr.-old children: an explorxtory trial. Perceptual and Motor Skills 2008; 106:745-734.

Fox, K. R., \& Wilson, P. M. (2008). Self-perceptual systems and physical activity. Advances in sport psychology, 3, 49-64.

Gallahue D.L., Donnelly F.C. Developmental Physical Education for all Children Movement

Goodway, J. D., Ozmun, J. C., \& Gallahue, D. L. (2019). Understanding motor development: Infants, children, adolescents, adults. Jones \& Bartlett Learning.

Graf, C., Koch, B., Kretschmann-Kandel, E., Falkowski, G., Christ, H., Coburger, S., ... \& Predel, H. G. (2004). Correlation between BMI, leisure habits and motor abilities in childhood (CHILT-project). International journal of obesity, 28(1), 22-26.

Hardman, K. (2002). Council of Europe Committee for the Development of Sport (CDDS), Report on School Physical Education in Europe. MSL-IM 16 (2002) 9. Strasbourg, Council of Europe

Hickson, C., Robinson, D., Berg, S. and Hall. (2010). Active in the North: School and community physical activity programming in Canada. International Journal of Physical Education, 2. pp. 16-30.

Jan, S. (2009). Shape it up: a school-based education program to promote healthy eating and exercise developed by a health plan in collaboration with a college of pharmacy. Journal of Managed Care Pharmacy, 15(5), 403-413.

Kelder, S. H., Mitchell, P. D., McKenzie, T. L., Derby, C., Strikmiller, P. K., Luepker, R. V., \& Stone, E. J. (2003). Long-term implementation of the CATCH physical education program. Health Education \& Behavior, 30(4), 463-475. 
Kim, S., Kim, M. J., Valentini, N. C., \& Clark, J. E. (2014). Validity and reliability of the TGMD-2 for South Korean children. Journal of Motor Behavior, 46(5), 351-356.

L.E. Robinson The relationship between perceived physical competence and fundamental motor skills in preschool children Child: Care, Health and Development, 37 (4) (2011), pp. 589-596,

Lieberman, L. J., Houston-Wilson, C., and Kozub, F. (2002). Perceived barriers to including students with visual impairments in general physical education. Adapted Physical Activity Quarterly, 19(3), pp. 364-377

Lopes, V. P., Saraiva, L., \& Rodrigues, L. P. (2018). Reliability and construct validity of the test of gross motor development-2 in Portuguese children. International Journal of Sport and Exercise Psychology, 16(3), 250-260.

Lopes, V. P., Stodden, D. F., Bianchi, M. M., Maia, J. A., \& Rodrigues, L. P. (2012). Correlation between BMI and motor coordination in children. Journal of Science and Medicine in Sport, 15(1), 38-43.

M. Fahimi, M. Aslankhani, M. Shojaee, M. Beni, M. Gholhaki The effect of four motor programs on motor proficiency in 7-9 years old boys Middle-East Journal of Scientific Research, 13 (11) (2013), pp. 1526-1532

McKenzie, T. L., Alcaraz, J. E., Sallis, J. F., \& Faucette, F. N. (1998). Effects of a physical education program on children's manipulative skills. Journal of Teaching in Physical education, 17(3), 327-341.

Murphy, C., Routen, A., \& Tones, S. (2014). World-wide Survey of School Physical Education: Final Report 2013.Valentini, N. C. (2012).

Okely, A. D., Booth, M. L., \& Chey, T. (2004). Relationships between body composition and fundamental movement skills among children and adolescents. Research quarterly for exercise and sport, 75(3), 238-247.

Özer D.S., Özer K.Çocuklarda Motor Gelişim.Nobel Yayınları.2009.

Pagona, B., \& Costas, M. (2008). The development of motor creativity in elementary school children and its retention. Creativity Research Journal, 20(1), 72-80.

Sallis, J. F., McKenzie, T. L., Alcaraz, J. E., Kolody, B., Faucette, N., \& Hovell, M. F. (1997). The effects of a 2-year physical education program (SPARK) on physical activity and fitness in elementary school students. Sports, Play and Active Recreation for Kids. American journal of public health, 87(8), 1328-1334. 
Sugino, T., and Mimura, Y., (2013). Women and Physical Education in the Globalized World: The Case of PE in Vietnam. Unpublished Paper.Ulrich D.A.,Test Of Gross Motor Development Examiner's Manual,Pro-Ed Publisers 2nd Edition 2000.

Valentini, N. C. (2012). Validity and reliability of the TGMD-2 for Brazilian children. Journal of motor behavior, 44(4), 275-280.

Vickerman, P. (2007). Training physical education teachers to include children with special educational needs: Perspective from physical education initial teacher training providers. European Physical Education Review 13(3): 385-402.

Welk, G. J., \& Eklund, B. (2005). Validation of the children and youth physical self perceptions profile for young children. Psychology of Sport and Exercise, 6(1), 51-65.

Whitall, J. (2003). Development of locomotor co-ordination and control in children. Development of movement coordination in children: Applications in the field of ergonomics, health sciences and sport. London: Routledge, 251-270.

Wrotniak, B. H., Epstein, L. H., Dorn, J. M., Jones, K. E., \& Kondilis, V. A. (2006). The relationship between motor proficiency and physical activity in children. Pediatrics, 118(6), e1758-e1765. 